\title{
Does Purchasing Make Consumers Complicit In Global Labour Injustice?
}

\begin{abstract}
Do consumers' ordinary actions of purchasing certain goods make them complicit in global labour injustice? To establish that they do, two things much be shown. First, it must be established that they're not more than complicit, for example that they're not the principal perpetrators. Second, it must be established that they meet the conditions for complicity on a plausible account. I argue that Kutz's account faces an objection that makes Lepora \& Goodin's better-suited, and defend the idea that consumers are complicit in at least two of the ways distinguished by the latter. In the final section of the paper, I consider whether consumers' responsibility for complicity in global labour injustice is likely to be as strong as responsibility from another source, namely benefiting from that injustice.
\end{abstract}

Keywords: Complicity, ethical consumption, labour injustice, global injustice, benefiting, Kutz

Author information: Holly Lawford-Smith, University of Melbourne

\section{Acknowledgements}

I'm grateful to audiences at the Society for Applied Philosophy Conference, Edinburgh, 3rd-5th July 2015, and the Nuffield Political Theory Seminar at the University of Oxford, 7th March 2016; Dominic Roser and Stephanie Collins for their thoughtful comments on the written version of the paper; Dan Halliday for useful discussion; and two anonymous reviewers for Res Publica for helpful comments and suggestions.

\section{§ I. Complicity in Global Labour Injustice}

In many parts of the world, people work in terrible conditions. Not only are there people experiencing the worst kinds of violations, including slavery, forced prostitution, forced surrogacy, child labour, and indentured servitude; but there is also widespread exploitation of labour. One way to understand this is in terms of rights violations. ${ }^{1}$ The United Nations Declaration of Human Rights states that

$1 \quad$ Although I've just mentioned rights, I'll actually remain neutral in this paper on the exact nature of the labour injustice, about which there is lively discussion elsewhere. It might be that a worker has rights against certain kinds of treatment; it might be that her work may not leave her below a certain baseline level of wellbeing. The injustices may be a matter of working conditions, working hours, pay, non-discrimination, respect, or otherwise. The novel focus in this paper is on what the moral implications are for consumers involved through purchases in those injustices, rather than on the specific nature of the injustices themselves. I will use 'injustice' rather than 'harm' deliberately throughout the paper, in order to respect the intuition that it's not possible to 
everyone has the right to 'just and favourable conditions of work' (Article 23(1)), to 'just and favourable remuneration ensuring for himself and his family an existence worth of human dignity' (Article 23(3)), and to 'reasonable limitation of working hours' (Article 24). To give one familiar example, there are some 4,500 garment factories in Bangladesh, whose economy is almost entirely dependent on them. Many of the factories are unsafe, lacking windows, fire escapes, and emergency exits (Riley 2013). At least 657 people were killed in a building collapse in 2013, and more than 100 people were killed in two factory fires in 2012 (ibid). The average worker is paid between 10 and 30 cents per hour (ibid). The majority of workers are paid around the monthly minimum wage, which is $3 / 5$ ths of what would be the minimum required to provide food, shelter, and education to a family (War on Want 2017). These factory workers work 14-18 hour days, 7 days a week, some with only a 4.5 hour break between shifts (ibid). $85 \%$ of these exploited workers are women; sexual harassment and discrimination is common and employers do not provide maternity leave (ibid). The Bangladeshi garment industry "is an industry where the workers are not just exploited and forced to work in an environment of harassment, violence and abuse, but where basic guarantees of safety have been thrown to the wind" (John Hilary from War on Want, quoted in Kelly 2013). Working conditions are neither just nor favourable; remuneration for work is neither just nor favourable and fails to secure for workers and their families a dignified existence; and working hours are far from reasonably limited. ${ }^{2}$

This paper is not, however, about the injustices inflicted on a daily basis upon exploited workers, but about the relationship to those injustices that consumers stand in. Many, if not all, individuals alive today are involved in some

both harm someone and make her better off (although cf. Shiffrin 2012), while acknowledging that sometimes labour injustice makes a person better off-e.g. because it gives her a source of revenue when she would have otherwise had none.

2 I accept that it's less bad for a person to have her labour exploited than for her to remain in extreme poverty. But only a view on which the worst case and nothing else counts as injustice will serve to dismiss the moral question of responsibility for exploitation. That's not to accept the converse, namely that only the best case counts for justice, but simply to say that among the many and varied more-and-less-ideal ways the world can be, questions about moral responsibility are not limited to the extremes. We can agree that the world could be worse, while simultaneously asking who's responsible (looking backwards) for the world not being better than it is, and who's responsible (looking forwards) for making it better than it is. 
way or other with this kind of global labour injustice, even if only through the ordinary products they buy as consumers within a global economy. In this paper I'll ask whether that involvement can be captured under the heading of complicity, in particular whether consumers' ordinary acts of purchasing goods can make them complicit in the injustices involved in the production of those goods. I'll argue that it can, and that consumers can bear moral responsibility for this kind of complicity. Of course, if the involvement of consumers in global labour injustice implicates them in a way that is stronger than mere complicity, then we have reason to focus on that stronger implication. For that reason, in $\S$ II I'll ask whether it's plausible to think of consumers as the principal authors of global labour injustice. I’ll argue that it isn't. In § III I'll ask whether consumers are instead joint authors - along with others-to the wrongdoing. I'll argue that they're not. Having made the case that both of these possibilities fail to capture the involvement of consumers with global labour injustice, the path is open in $\S$ IV to discuss whether consumers' involvement with global labour injustice can be captured by one of the various forms of complicity. I'll argue that it can, and in $\S \mathrm{V}$ ask what responsibility attaches to this consumer complicity.

\section{$\S$ II. Consumers as Principal Authors of Global Labour Injustice}

We start with the question of whether consumers taken together are the principal wrongdoer. Why ask this question? Surely we can take for granted that corporations owning and running sweatshops are the principal authors of sweatshop injustices, which would make consumers joint authors at best? Let's consider the alternative. Rather than thinking of corporations as the principal authors of injustice and consumers as 'downstream' recipients of goods implicated in those injustices, we can think of consumers demanding all sorts of products without any concern for justice in their production, and corporations stepping in to answer that demand. A model of corporations as largely mechanistic, operating within the strict constraints of the law but primarily driven to maximize profit, is conducive to that thought. On that model, if ethics is to enter the picture it'll have to come from the demand side (what consumers are willing to buy) rather than the supply side (corporations placing ethical constraints on their own operations). Maybe it's corporations who are complicit in the injustice consumers 
demand, rather than the other way round!

Consumers taken together are a cause, if not the only cause, of global labour injustice in two ways. They're a cause by omission in virtue of their influence on corporations' practices. If consumers taken together wouldn't purchase goods produced in sweatshops, for example, then corporations wouldn't produce goods in sweatshops. The latter's imperative is to sell, and their ability to sell depends on what their customers will buy. The fact that consumers buy unjustly-produced goods causes corporations to continue to produce goods unjustly, and this links consumers to those future injustices (which would have been otherwise had the latter's consumption patterns been otherwise). Consumers are also a cause by action in virtue of their direct influence on demand in the market. When they buy sweatshop $t$-shirts, for example, end-retailers and intermediary companies order more sweatshop t-shirts to be produced by the corporations. This links consumers to these future injustices (which, similarly, would have been otherwise had consumers' consumption patterns been otherwise).

But it's not sufficient to being morally responsible for injustice to merely be a cause of it. Natural disasters cause harms - harms that would be injustices if inflicted deliberately - and we don't think that natural disasters are morally responsible for injustice. Some further property is needed, in conjunction with causation, such as intention, or foreseeability, or ability to do otherwise (and so on). When it comes to groups, that further property is control. Consumers taken together may be a cause of global labour injustice, but in order to have an obligation not to cause global labour injustice (which they would be violating), or to be responsible for having caused global labour injustice in the past (which they would then come to have obligations to make up for), they must have control over that causing. Consumers taken together are an aggregate. Some aggregates of individuals have the control necessary to bear obligations (forward-looking), and to bear responsibility (backward-looking) for their actions after the fact. Others do not. What distinguishes the one from the other is the extent to which they are organized, usually under a decision-making procedure. And it is clear that consumers taken together-all of them, from all around the world-lack control over what they do together. If one of their number were to say 'we should stop 
exploiting the poor!' an appropriate response from another of their number would be 'what 'we'?' Because we can't attribute obligation (before the fact) or responsibility (after the fact) to consumers for what they cause together, it's not worth dwelling too much on the fact that consumers cause global labour injustice. But what about consumers taken individually?

To answer this question, we need to be very careful about how we specify the injustice. If we take a holistic description like 'global labour injustice', which we've been working with so far, then it'll be clear that no individual consumer causes this, whether by action or by omission, through her purchases. ${ }^{3}$ The injustice is just too big, the individual consumer just too small. But what if we work with more fine-grained descriptions - global labour injustices, plural-which together make up the holistic description? An example would be the violation of the labour rights of a particular worker in a particular location at a particular time, or, the fact that a particular worker in a particular location at a particular time falls far below a minimum level of wellbeing. This characterization of the injustices, indexed to person, location, and time is a way of assigning specific temporal segments of the ongoing holistic injustice to individual consumers. Might individual consumers cause these?

This depends on a number of things: the production practices of the relevant corporation; the way reordering of products works between end-retailers, intermediaries, and corporations; and whether we use a model of 'triggering' injustices or jointly causing injustices (Kagan 2011). Some corporations use production lines, where each worker completes one part of a sequence required for the production of the relevant good, and some have workers complete all parts of the sequence. Some retailers will order another product every time one sells, while others will order more of a product whenever 100 sell, or whenever 1000 sell (this will depend on the nature of the product). For a product completed in full by one worker, in combination with a strict connection between a product

3 It is conceptually possible for a large injustice by an aggregate to be caused by each of its many members, (i) if we take causation to be counterfactual dependence, and (ii) when the injustice depends counterfactually on each of the many members. This is analogous to when a confluence of events and actions must all come together to produce a unique outcome. Global labour injustice doesn't have this structure (it does not depend counterfactually on any particular purchase). 
being reordered every time one is sold (i.e. where the reordering threshold is 1), individual consumers can be the cause of a labour injustice against a specific worker at a specific time and in a specific place. For a product completed by many different workers in sequence, in combination with the same strict connection between a purchase and a reordering, individual consumers can be the cause of a labour injustice against a group of specific workers at a specific time and in a specific place. This gives us causation of injustice in a way that is 1-1 and 1-many.

There's also causation that is many-many. A model of 'triggering' injustice assigns causal responsibility to the very last purchase in a sequence that crosses the threshold necessary for retailers to reorder more of a product (Kagan 2011). ${ }^{4}$ On this model, an individual consumer can be a cause of injustice to one worker or to many workers, as discussed above. But a joint causation model takes all those purchases in the sequence to jointly cause the reordering, and therefore the injustice that goes along with it (Kagan 2011). This gives us a causal relationship that is either many-many or many-1. The group of purchasers who together caused a reordering of the product will cause labour injustice against one worker (if only one product is ordered and if it that product is completed in full by one worker) or against many workers (if more than one product completed in full by one worker is ordered, or if products completed by different workers in sequence are ordered).

But notice that only some purchases will cause injustice in this way. In addition to being the sole triggering cause or one of the joint causes of injustice

$4 \quad$ I'm departing from Kagan's terminology here in using 'triggering' only for cases where the cause is the last purchase in the sequence, and 'joint causation' for cases where the cause is all purchases in the sequence. Kagan himself discusses both kinds of case under the heading of 'triggering', and says that the main issue for second kind of cases is whether there is a cohort of the right size to hit the re-ordering threshold but not exceed it (if it's exceeded, then we have an overdetermination case, and no purchase is a cause). So there's the expectation of being the sole trigger in what I'm calling a triggering case, and there's the expectation of being a member of a cohort of the right size in what I'm calling a joint causation case. Julia Nefsky has objected to Kagan's analysis of triggering cases on the grounds that contributions will not always be prohibited on consequentialist grounds, as Kagan thinks they will (Nefsky 2012). I agree with her on this point: whether they are prohibited depends on the probability of being a trigger or part of the joint cause, and on the disvalue of what is caused. But this does not imply that there are no cases where purchases are not prohibited on consequentialist grounds, so this particular objection does not affect my argument. 
to a specific worker or a group of workers, an individual purchase might overdetermine the injustice (it would have caused a reordering if others' purchases hadn't), and might underdetermine the injustice (there are insufficiently many purchases to reach the threshold, so there is no reordering). For this reason, we can only say that an individual consumer's purchase sometimes causes injustice, because the purchases is only sometimes a sole or joint cause of an injustice, instead of an over- or under-determiner.

Moreover, even when the individual consumer's purchase is a sole or joint cause of injustice against an individual or group of workers, whether she is morally responsible for that purchase depends on what she knows and has control over. Most consumers know that there is (are) global labour injustice(s), and can reasonably expect that their own purchasing actions are intersecting with others' purchasing actions in order to create demand in the market. (That is to say, most people will be cognizant in general of the anti-sweatshop movement, the fair trade movement, the existence of exploited labour abroad, and so on). But almost no one knows the specific production processes involved in the products they buy, or where the various reordering thresholds are set for different end-retailers and for different kinds of products, or where their own action falls in a causal sequence such that their purchase would make them a triggering cause of a reordering, or a joint cause together with others.

Of course, epistemic uncertainty does not fully preclude obligation or responsibility. We can run the probabilities in order to arrive at an expectation of individual consumers' causation of global labour injustice. People make purchases all the time (especially in rich countries). Those purchases will sometimes be a sole or joint cause of injustice, and won't be a mere cause in the way a natural disaster would be. Thus consumers can reasonably expect that through at least some of their purchasing actions, they'll be a cause of global labour injustices. Because they have general obligations not to cause harm, and to repair harm they have caused, this appears to be a way to generate consumer responsibility for global labour injustices.

However, there are two problems with accepting this account of consumer obligations. The first is that it is not obviously impermissible that an individual accept some probability of risk in her actions. If the probability of injustice 
against one or a group of workers through a purchase is too low, or the probability of the injustice is reasonably high but the injustice itself is too minor (as perhaps the 60 seconds of a specific sweatshop worker's day spent sewing two sleeves into a particular set of $t$-shirts might be $)^{5}$ it might be inadequate to rendering the purchase impermissible. We could take a hard line here and say that no risk of injustice is permissible, however small; we could take a moderate line and say that a minor risk of injustice is permissible in the pursuit of morally important ends, but that consumption is rarely morally important.

The second problem is more damning. As mentioned already, consumers may be a cause, but they're not the only cause; and most importantly, they're not the principal cause. Their ability to cause global labour injustices is dependent on the practices of companies and corporations. At most, consumers' causing is a byproduct of companies and corporations' causing. The principal authors of injustice when it comes to global labour injustice are the companies and corporations employing workers under exploitative conditions, degrading the environment, and so on. Consumers stand in a certain relation to these companies and corporations. In the next section I'll give up the idea of consumers as principal authors, in favour of taking companies and corporations as the principal authors, and considering whether consumers might count in the slightly weaker way as joint authors together with them.

\section{$\S$ III. Consumers as Joint Authors of Global Labour Injustice}

What about characterizing consumers as joint authors instead? This is to ask about consumers' relationships with others, in particular companies and corporations, who are involved in the perpetration of global labour injustice. If that relation is strong enough, consumers may count as joint authors, perpetrating the injustice by acting together with others. Manufacturing companies and corporations are among the principal wrongdoers, perpetrating a

5 This is further complicated by the fact that (at least for those earning a salary rather than wages) some number of hours and some amount of money would suffice to labour justice, so that it is only after the worker has worked these hours and earned that amount of money that her labour will count as exploited and those who exploit it will count as authoring injustice. That means some purchases will cause work that is not yet an injustice, and some will cause work that is, and this further reduces the probability of any given purchase causing injustice in the way explained above. 
range of injustices from the exploitation of workers and violation of workers' basic labour rights, through to the infliction of suffering upon animals, and the pollution and degradation of the natural environment - all in the name of greater profit. Are consumers guilty of acting as joint authors, together with companies and corporations, in the production of these injustices? In their (2013), Chiara Lepora and Robert Goodin distinguish four ways in which individuals might act as joint authors with others: through full joint wrongdoing, conspiracy, cooperation, and collusion (Lepora \& Goodin 2013, pp. 36-41).

In full joint wrongdoing, parties to the wrong make identical contributions to a wrongful action (ibid, pp. 36-37). This represents the limiting case in Lepora $\&$ Goodin's discussion, they think it characterizes no real case. Consumers fail to provide a counterexample to that thought. Whatever it is consumers do (in general, purchasing and consuming goods), it's something quite different to what companies and corporations do (in general, producing and distributing goods). In conspiring, parties to the wrong agree together to perform the wrongful action (ibid, pp. 37-38). The unique wrong of conspiracy is located at the point of agreement, rather than at the point of performance of the action that was agreed upon. It is implausible that consumers taken together conspire with companies and corporations, because the fact of their being an unorganized aggregate precludes their agreeing to anything. It's also implausible for most consumers taken individually that they conspire with companies and corporations, simply because what companies and corporations do is rarely decided in that way (namely, in discussion with customers, but also, dependent on any particular customer). There are exceptions to this generalization for companies and corporations who have very few, very influential customers. Producers of highend luxury goods are presumably like this. Very few people can afford to buy haute couture, for example, and those who can may plausibly be in a much more influential relationship with the producers and designers of the clothing such that they count as conspiring in wrongdoing together with those producers when the garments are produced in conditions of injustice.

Cooperation and collusion are similar, in that they require parties to a wrongful action to share in both the plan to perform that action and the execution of that plan, with collusion having the additional feature of the cooperation being 
secretive or occluded (ibid, pp. 38-39 \& 39-41). The same lack of organization that prevented conspiracy in consumers taken together also prevents cooperation and collusion. Lacking a decision-procedure, consumers taken together do not have the functional equivalents of beliefs, preferences, desires, and decisions necessary to make them capable of agreeing, planning, planning secretly, or executing in concert the elements of a plan. And the same insignificance that made conspiracy implausible in consumers taken individually also makes cooperation and collusion implausible, although with the same exception for influential customers of small or high-end companies and corporations. In general, for most consumers most of the time, they won't stand in a relationship of full joint wrongdoing, conspiracy, cooperation, or collusion with companies and corporations in their perpetrating of global labour injustices. Thus we can now turn to complicity, and whether this provides a plausible way of capturing the involvement of individual consumers in global labour injustice.

\section{$\S$ IV. Complicity in Global Labour Injustice}

To be complicit in global labour injustice, consumers must be distinct from the principal wrongdoer, rather than part of it, and then stand in the right sort of relation to it. There are two prominent theories of complicity, one due to Christopher Kutz (2007a, 2007b), and the other to Lepora \& Goodin (2013). I'll take these in turn, arguing against the former and in favour of the latter.

Kutz (2007a) proposes an account of complicity which has as its core component participatory intentions. These are intentions of a certain kind, connected to actions of a certain kind, in particular, an intention that an action make a contribution to a collective end. Kutz draws on the testimony of persons involved in the bombing of Dresden during World War II, commenting that 'their sense of accountability was grounded not in an assessment of the differences they had made as individuals, but in an act they had performed together' (ibid, p. 121). It's the idea of intentionally participating in a collective endeavor, rather than causing an outcome to be one way rather than another, that links individuals to the consequences of what collectives do (ibid, p. 138). On this basis, Kutz

$6 \quad$ Here 'what collectives do' is not meant to imply a commitment to collective agency, only to outcomes that are brought about by the actions of multiple persons. 
proposes the Complicity Principle:

'I am accountable for what others do when I intentionally participate in the wrong they do or harm they cause. [...] I am accountable for the harm or wrong we do together, independently of the actual difference I make' (ibid, p. 122).

Consider the following example. Manu knows from overhearing their conversation at work that some of his workmates want to play rugby in the park near his house in the afternoon. He happens to be in the park at the relevant time, and notices a group of people starting to set up for a picnic right in the centre of the park. He goes over and politely asks them if they wouldn't mind relocating closer to the edge of the park, so that his workmates can play their game of rugby as planned. In doing so, Manu has performed an action (asking the group of people to relocate their picnic) with the intention of that action being a contribution to a collective end, namely, the playing of a game of rugby by his workmates. So long as there really is this collective end (it does not count if Manu performs this action under the illusion that there's a collective end of playing rugby), his action together with the relevant participatory intention is sufficient to make him complicit in the eventual rugby-playing. Nothing should seem particularly problematic about this yet. After all, complicity is about standing in a certain relation to a principal actor or the actor's action, and here Manu has done something minor (clearing the park) to facilitate the primary action (playing the game) by his $\mathrm{co}^{-}$workers. If I'd put this in terms of a morally culpable action like a robbery rather than a sports game, most people would presumably share Kutz's intuition that Manu's action makes him complicit.

A natural question to ask about Kutz's Complicity Principle is whether it's one-directional, tying those individuals like Manu who perform actions intended as participations in a collective end to the collective's end, or bi-directional, also tying others who participate in the collective's end to Manu's participatory action. This question doesn't arise in cases like the Dresden bombing, because the bombs dropped by individual pilots together constitute the collective end. There's no meaningful difference in that case between an individual being accountable for the overall bombing in virtue of her participation in it, and being accountable for the overall bombing in virtue of being accountable for what others 
do in pursuit of the collective end to which she also contributes. But the question does arise in the rugby case, because clearing the field is not constitutive of playing a game of rugby (it's a precondition on playing, but it isn't part of that playing). Kutz's comment 'when we act together, we are each accountable for what we all do, because we are each authors of our collective acts' (ibid, p. 138) is ambiguous on this point: does what we all do include what we each do in service of what we all do? But there are two passages that strongly support bidirectionality:

'Intentional participation provides a special basis for ascribing individual members' actions to the group as a whole, and to the group members individually' (ibid, p. 138).

'If a set of agents' participatory intentions overlap, then the will of each is represented in what each other does qua group member, as well as what they do together' (ibid, p. 141).

So it's not only that an individual becomes accountable for the collective's end by acting with participatory intent, but also that the collective becomes accountable for what the individual does in pursuit of its end, by being participated in. But this seems to implausibly over-generate accountability. Consider a minor modification to the rugby case. In this version, instead of politely asking the picnickers to move, Manu is aggressive and disruptive. He shouts at the picknickers to move, he kicks some of their plates and cups out of the way, and spits into one of their bowls of salad. He performs these actions with participatory intent. In the same way as in the original case, this looks sufficient to link Manu to the playing of the rugby game (not that there's anything wrong with playing rugby, but if there were he'd have a share in the accountability for the playing). But in this case it looks much less plausible that his group of workmates become reciprocally linked to what Manu has done in the service of their playing rugby in the park. Kutz's attempt to vindicate the idea that 'participation entails implication' (ibid, p. 144) looks plausible in implicating individual participants in collective ends (like the overall bombing of Dresden, or the workmates' playing of the rugby game), but not plausible in implicating the collective, and therefore its implicated participants, in the individual participatory actions (like an individual plane's dropping of a bomb, or Manu's bad behaviour with respect to the picnickers). 
Of course, this is not yet a reason to throw out the account altogether. We could simply make a modification in order to generate one-directional rather than bi-directional accountability, and think about where that would get us when it comes to the implication of individual consumers in global labour injustice. That would leave us with the claim that actions performed with participatory intent are sufficient to tie individual consumers to those labour injustices that are collectively caused. But given that the primary injustice is done by corporations and companies, not consumers taken together, this doesn't get us very far. (We can't ask whether purchases made by individual consumers are actions done with the intention of participating in injustices done by companies and corporations such as the exploitation of workers and environmental degradation, because these are others' injustices, not our injustices). We need a collectively-cased outcome such as the bombing of Dresden, where individual contributions to this outcome don't make a causal difference sufficient to individual culpability, but where contributions taken together constitute the (holistically-described) injustice, and where participation in the collective action is sufficient to implicate individuals in the outcome.

In the case of consumption, that would have to be something like failing to collectively resist global labour injustice. Then the question would only be whether we could read individuals' purchases as being done with the intention of participating in that collective failure. That seems implausible. People make purchases for all sorts of reasons, and for no reason. It's obviously an empirical question, but it seems unlikely that many, if any, intend their purchases to be contributions to the failure of collective resistance to global labour injustice in this way. So individual purchases are unlikely to make individuals complicit in global labour injustice on this modified version of Kutz's view. (The other alternative would be to make yet another modification to Kutz's view. As it stands, my action must be performed with the intention that it be a causal, normative, or expressive participation in our ends (the ends of a group-however unorganized - of which I am a part). It's unlikely that there's anything much that we as consumers have as ends. But we could instead allow that my action be performed with the intention that it be a participation in another's ends (such as the corporation's). This is inimical to Kutz's purpose, because he wants 
complicity as a form of joint responsibility. But it seems to be compatible with a more colloquial understanding of complicity). Then at least consumers would have a chance of implication in the primary injustice, rather than merely in failure to resist that injustice. But even with that further modification, the account will fail to generate complicity, for the same reason just given). Kutz's account fails to generate complicity, either because as he actually formulates it, it over-generates accountability; or because with either modification, it fails to implicate ordinary consumers. We have to look elsewhere if we still want a possibility of finding consumers complicit in global labour injustice.

We considered already Lepora \& Goodin's category which included the different ways in which consumers might be joint authors with others - paradigmatically companies and corporations - in global labour injustice. On their account, there is complicity only if there is not one of these stronger relations. I have argued that there is not. In characterizing complicity, Lepora \& Goodin distinguish four 'conceptual cousins' of complicity from what they call 'complicity simpliciter', which also comes in the more precise type 'complicity by collaboration' (Lepora \& Goodin 2013, p. 41). These cousins do not normally involve causal contribution to the primary injustice, while complicity simpliciter and collaboration both do (without yet constituting it). The cousins include conniving, condoning, consorting, and contiguity (Lepora \& Goodin 2013, pp. 43). At least two of the cousins apply defeasibly to consumers, and there's very clearly complicity simpliciter. I'll address the cousins first, then move to complicity simpliciter including the more specific complicity by collaboration.

Consorting involves habitually spending time with those who do wrong (ibid, pp. 49-50), and contiguity involves a proximity to the wrongdoer which either reveals bad character or acts as a signal of tacit assent to the wrongdoer (ibid, pp. 50-51). Condoning involves forgiving or pardoning the wrong (ibid, pp. 47-49). Conniving involves ignoring, deliberately overlooking, or tacitly consenting to the wrong done by the primary wrongdoer (ibid, pp. 44-47). The first two will be non-starters for most consumers, either because of the metaphysics of collectives like 'companies' and 'corporations' which make it hard to see what a consumer 'spending time with' or 'being in proximity to' those would mean, or because even if we identified companies and corporations with key 
individuals (such as the CEO), few, if any, consumers are likely to be involved in consorting or contiguity with those individuals, and in any case not by way of their consumption practices.

How about condoning and conniving? Consumers (taken individually) don't seem to be in a position to forgive or condone, at least not in the way Lepora \& Goodin seem to have in mind. They discuss cases like the IMF condoning defaults on repayments of sovereign debt (ibid, p. 47), and a President's condoning the actions of an associate (ibid, p. 49), both of which are done from a position of authority, and both of which involve explicit communication of the pardon or forgiveness. But perhaps these examples are misleading. If we set aside the (implicit) requirement of being in a position of authority, or of making an explicit communication, can we then read forgiveness or pardoning off consumers' actions of purchasing the relevant goods?

There are a great many reasons for why a consumer might purchase the specific goods she does, and only some of these involve her signaling forgiveness or pardoning to the producer of the way in which those goods were produced. These reasons include the proximity of retail outlets to her home, work, or normal routes; 'nudge' tactics employed by her government; her budget and the amount of cognitive effort she already expends in managing it; and competing moral concerns which trump or dominate a concern for global labour justice. Absent any such confounding reasons, the purchase might well express forgiveness or pardoning of the injustices involved in the goods' production. So at most, consumers are defeasibly complicit in global labour injustice by condoning it: those without confounding reasons, who are aware of the injustice and go ahead and buy the goods anyway, probably are. But notice further that consumers' reasons for their actions are transparent neither to other consumers nor to the companies and corporations from which they buy-so even if there's actually condoning going on, it's not yet the case that the mere act of purchasing communicates condoning to the corporation.

How about conniving? An initial problem in applying this idea is to do with consumers' temporal proximity to the injustice. Here's an ordinary case of conniving: a policeman turns a blind eye to a theft because the thief is his brother (Lepora \& Goodin 2013, p. 46). The injustice happens at much the same time as 
the conniving in this case. But that's not true for consumers. There are two directions in which their purchases might have an impact on the injustice perpetrated by the companies and corporations. The first is backward, the second is forward. We've already discussed the forward-impacting direction, in discussing the effect of consumers' purchases on demand and the way this causes future injustices. The backward-looking direction is less direct, and it involves the failure to sanction perpetrators of injustice. For example, imagine that your friend is recounting a travel adventure and includes a description of a racist comment that he made to someone on the trip. The injustice has already happened (it happened on the trip), and so your failing to say something does not make you complicit in the direct way that the policeman was complicit in his brother's theft in Lepora \& Goodin's example. But nonetheless, if you let this pass without comment, you are failing to sanction your friend for racist conduct, and in this way you are still deliberately overlooking an injustice.

As with condoning, the same is defeasibly true for consumers. By the time they buy a sweatshop t-shirt from a retail outlet, the injustice involved in the production of that $t$-shirt (the conditions in which it was produced, the suffering of the worker who produced it, the unfair wages the worker was paid to produce it, and so on) has already long since been done. Nonetheless, there's an appropriate response to injustice of this kind, and if there are no more compelling explanations of their purchase, then consumers manifestly fail to display that response when they make the purchase. By failing to display the right response to injustice, they may send a signal that they are for whatever reason willing to overlook the injustice. In this way, they also connive in the original injustice, as well as making future injustice more likely (by signaling that they will not resist it). Perhaps if consumers sanctioned companies and corporations in other ways, their purchases would not necessarily act as signals of this kind. But most don't.

We can't make recourse to the claim that consumers are unaware of the effect of their purchases, either. There has been considerable media attention devoted to issues like the mining of conflict minerals (present in most personal electronics including smartphones), sweatshops (producing the bulk of high-street clothing), fair trade, and so on. Those consumers who lack confounding reasons for their purchases are choosing to deliberately overlook the global labour 
injustice that both has been involved, and will be involved, in the products they buy. Consumers are defeasibly complicit (which will likely amount to the claim that some are complicit and some are not) in global labour injustice by conniving in both a forward-looking and a backward-looking way with the companies and corporations that perpetrate it. ${ }^{7}$

However, whether we can attribute them obligations or responsibilities in light of this depends on whether they're justified in or excused from being complicit in this way. I've already said they probably don't have access to ignorance as an excuse. But I mentioned in discussing condoning that there are many different reasons for why consumers make the purchases they do. Given that we can order from sweatshop-free companies like American Apparel and PeopleTree online, it's implausible to think that the proximity to my usual travel routes of a retailer selling sweatshop goods is an excuse for my buying clothing there. But the fact that I'm extremely poor and genuinely can't afford the higher price of a non-sweatshop $t$-shirt without violating other moral obligations with worse overall costs might be. Likewise the fact that I'm committed to the mitigation of and adaptation to climate change and put all my efforts into reducing my own and others' greenhouse gas emissions might be. ${ }^{8}$ So how useful this kind of complicity will be in generating obligations and responsibilities to do something about global labour injustice (at the very least, to stop being complicit in that way) will depend on the proportion of consumers who don't have access to an excuse of the kind just outlined. It is my sense that this will still capture a reasonable portion of consumers. But it won't catch all of them-and perhaps that's exactly the right result.

7 It seems that there can be conniving in two different ways, and there might be a morally important distinction between the two. One can connive by omission, for example by failing to act as a good samaritan when confronted by an action on which one could easily intervene. But one can also connive by action, which is what consumers do when they actively buy clothing produced in sweatshops. Many people have the intuition that injustice by action is morally worse than injustice by omission, so the fact that this kind of conniving happens by action (purchasing) rather than omission (failing to taken an action that one could take) might help to generate a stronger kind of responsibility or obligation as a result.

8 The idea here is that when it comes to non-ideal contexts requiring 'moral triage', it's permissible for an individual to neglect moral considerations in one domain for the reason that she does as much as she ought to do, just in another domain (i.e. she reaches the threshold on demandingness, which is not domain-specific). 
We could stop here, having shown that there are (defeasibly) at least two kinds of complicity, namely complicity by condoning and by conniving, that consumers taken individually are guilty of. But for those who are worried either about the defeasibility clause, or that condoning and conniving will see too many consumers' purchases justified or excused, there's still the final category of complicity simpliciter to consider. On Lepora \& Goodin's account, there's complicity simpliciter only when there are none of the conceptual cousins (and likewise none of the relationships that make consumers joint authors). Here's what they say about those involved in complicity simpliciter:

\footnotetext{
Those who are complicit simpliciter 'contribute to another's wrongdoing' [...] contribute causally (or could have been expected to contribute causally) to the implementation of the principal wrongdoing [...] often perform contributory acts that 'give access' to the principal wrongdoing, facilitating it or perhaps even making it possible. [...T]hey might induce or incentivize the wrongdoing $[\ldots]$ or encourage it $[\ldots]$ or make it easier to perform (Lepora \& Goodin 2013, p. 41-42).
}

Crucially, those who are complicit know or should know that by acting they advance the intentions of the principal (ibid, p. 42). In discussing inducing and incentivizing Lepora and Goodin use the example of a thief who would not have stolen a painting were there not a 'fence' ready and willing to sell it (ibid). (This may bring to mind the relation between consumer demand and corporations' production discussed earlier; I'll return to this in a moment).

Complicity by collaboration is a more precise version of complicity simpliciter (ibid, pp. 42-43). Collaboration involves a contribution to the principal's plan coming to fruition (but a contribution that falls short of partly constituting the primary wrong, which would put its author into the category of being a principal or joint author) (ibid, pp. 41-43). The collaborator 'accepts and acts upon' the plan, without necessarily adopting it as his own (ibid, p. 43). Collaboration is yet another case where it matters a lot whether we're asking about consumers taken together or consumers taken individually. Consumers taken together do make a significant contribution to the principal's plan coming to fruition. Without them, companies and corporations could not make a profit from selling goods whose production involved global labour injustice. But as we've 
discussed already, this is not of much use in assigning responsibility for complicity, because consumers taken together aren't the kind of group that can be responsible for what it has done, or obliged to do differently. So we have to ask instead about consumers taken individually. Here it's far less plausible that any individual consumer contributes to the principal's plan coming to fruition, because there is only a low probability of any consumer being a difference-maker relative to specific (i.e. finely-specified) global labour injustices, and virtually zero probability of their being a difference-maker relative to global labour injustice taken as a whole (although here the same exception discussed earlier, for influential customers of small high-end companies, applies).

Is difference-making more plausible in the case of complicity simpliciter? After all, it takes much less to induce, incentivize, encourage, facilitate etc. a corporation in doing injustice than it does to contribute to the coming to fruition of a corporation's plan to do injustice. Couldn't we claim that in making a purchase, the consumer sends a signal that she is willing to purchase these kinds of goods, and that incentivizes the company or corporation to produce more such goods, confident that they will sell? But this would be to oversimplify the actual structure of supply and demand. As outlined in $\S$ II, reordering is usually a matter of thresholds. A difference of plus or minus one purchase will very often not have any effect at all on what is produced (because the injustice is overdetermined by others' purchases, or because together with others' purchases it is still insufficient to the injustice), even if we focus on a very specific area of production - this particular kind of t-shirt, produced in this particular sweatshop, ordered by this particular company. Sometimes it will be the purchase to make the difference (it will be the one that triggers a reordering, or one of the purchases together sufficient to trigger a reordering), and in those cases the consumer will be guilty of complicity simpliciter. Just as for causation by the principal, the best way to avoid this problem of being sometimes-complicit-andsometimes-not is to run the expectations.

A consumer regularly engaged in purchasing goods whose production involves injustice has a particular probability of any one of her purchases making her complicit simpliciter in global labour injustice. The more purchases she makes, the more likely it is that she's been complicit simpliciter for at least one of 
them (if the expectation is $1 / 100$ then she can expect to have been complicit simpliciter after she's made 100 purchases). So the individual consumer is on expectation complicit simpliciter in specific (fine-grained) instances of global labour injustice. ${ }^{9}$

In summary, individual consumers are defeasibly complicit in global labour injustice in two ways, namely by condoning and by conniving, and non-defeasibly complicit in one way, namely by (expectation of) complicity simpliciter. The remaining question, of course, is what kind of responsibility or obligation this allows us to attribute to consumers, especially given the extent to which consumers might be excused from condoning and conniving. I turn to this question in the next section.

\section{$\S$ V. Consumer Responsibility Based on Consumer Complicity}

Consumers are complicit in global labour injustice in a few different ways, as just described. But are they morally responsible for this complicity in a way that would give them reason to take remedial action, or allow us to sanction them? Lepora \& Goodin make the following suggestion:

\footnotetext{
How morally blameworthy an act of complicity is is a function of four things: the moral badness of the principal wrongdoing; whether (and, insofar as it is scalar, by how much) the secondary agent crosses the threshold of moral responsibility for having contributed to it; how much of a contribution his act made (or might make) to the principal wrongdoing; and the extent to which the secondary agent shares the purposes of the principal wrongdoer (Lepora \& Goodin 2013, p. 97).
}

The first feature is how bad the wrongdoing perpetrated by the principal wrongdoer is (ibid, pp. 103-104). In the case of consumption, the question is how egregious the injustice suffered by workers is (I have been mainly talking in terms of violations of workers' labour rights, but we should also think about injustices

$9 \quad$ Notice that if the original model of consumers as the primary wrongdoer had been correct, then we'd be comparing two kinds of expected involvement: there the expectation of causing harm, here the expectation of being complicit. Being a cause of harm is usually thought to be worse than being complicit in harm, so if the original model had been correct we'd already have a more morally significant source of obligation for consumers. But that model was set aside earlier in the discussion, which is what makes complicity the best account of consumers' obligations. 
against animals - e.g. what amounts to torture in factory farms - and the environment). Presumably we should assess this in a fine-grained way, e.g. how bad the injustice against the workers in the particular sweatshop producing these t-shirts is, rather than holistically, e.g. how bad global labour injustice is taken on the whole. (On this point, see the complication raised in fn. 7).

The second feature, responsibility, itself involves three elements: voluntariness, knowledge of contribution, and knowledge of wrongness of principal wrongdoing (ibid, pp. 104-105). In the case of consumption, this means that consumers must make their purchases voluntarily (not be coerced into doing so, for example), that they could and should have known that their purchases would make a contribution to the principal's wrongdoing, and that the principal's action was that - a wrongdoing. This covers cases where consumers in fact didn't know, but culpably so, because it was possible for them to have known and something that they should have known. If any one of these three elements of responsibility is missing then the consumer isn't responsible for her act of purchasing. Most consumers will make their purchases voluntarily, and with knowledge of the principal's wrongdoing - at least general knowledge of the injustices involved in the production of goods like these, but sometimes also specific knowledge of the injustices involved in the production of these particular goods, by this particular company (chocolate, coffee beans, bananas, and sneakers are all good examples). It's possible to push back a little against voluntariness in some cases, particularly where there are no alternatives on the market that don't involve injustice (in which case it may be that the consumer has no reasonable alternative not to buy, but would yet strongly prefer to buy a good not implicated in injustice in the way the available goods are).

The most vulnerable element is knowledge of contribution. First of all, knowledge of contribution might be undermined. Companies go to great lengths to obscure the injustices in their production practices from the view of consumers, and for this reason it is not clear what the extent of consumer knowledge of injustice is. This is an empirical question that I can't hope to resolve here. Anecdotal evidence suggests some general knowledge; but the greater the number of cases where consumers lack knowledge, the less likely it is that consumers will meet the responsibility condition, and the lesser the number of cases where 
consumers lack knowledge, the more likely it is that consumers will meet the responsibility condition. So there may well be more complicity in global labour injustice for certain kinds of products (e.g. chocolate and coffee) and less for others (e.g. consumer electronics), despite the latter potentially involving worse injustices overall, because there is more transparency about the former than the latter. Second of all, the knowledge of contribution may be undermined by drop in the pond' beliefs, which is to say, consumers misunderstanding the way thresholds work in consumption and believing that no individual purchase ever makes a difference. (But it would also need to be false that they should have known, and this is less plausible.) A positive conclusion that consumers do often meet the responsibility condition is conditional upon their having knowledge of the contribution their purchase might make. I think they at least sometimes have that knowledge and so meet the condition, but others may disagree, and to that extent may be able to reject the conclusion that consumers are complicit, in multiple ways, in global labour injustice.

The third feature, contribution, requires assessing the extent to which the action could have been expected to contribute to the principal's wrongdoing (regardless of how things actually - possibly flukily - turn out). Contribution itself involves six elements: centrality, proximity, reversibility, temporality, planning, responsiveness (ibid, pp. 106-107). In assessing centrality, we would ask how central the consumer's act of purchasing an item is in terms of magnitude and probability of being essential to the principal wrongdoing. In assessing proximity, we would look at the proximity of the purchase to the wrongdoing. Reversibility is about whether the contribution is 'locked in' once performed, or can be undone. Temporality is about whether the action is part of a repeated pattern of similar actions or rather a one-off. Planning is about whether the consumer is a plan maker or only a plan taker relative to the principal wrongdoing. Finally, responsiveness is a matter of whether there's mutual responsiveness between the principal and the complicit agent. Lepora and Goodin suggest thinking of contribution as a weighted average of these six factors, for a score of between 0 and 100 .

Because proximity is probabilistic, no individual consumer has a high probability of being essential to the principal wrongdoing, and the magnitude of 
her contribution if she were would be low (the relevant number of seconds of the worker's day, for example). Purchases will be proximal to the injustice when they are the cause of a reordering, which any given consumer can expect her purchases to be, some of the time. With respect to reversibility, goods can be returned, but it's unclear the extent to which this will 'undo' the purchase's impact on demand (whether it does will depend on the policies of the endretailers). A given purchase will often be part of a repeated pattern of similar purchases for most consumers, because consumption is habitual. As already discussed, most consumers have nothing to do with the plan-making of the principal wrongdoers, even if they in some sense advance those plans by making purchases (or by not advancing the cause for the goods to be produced in a just way).

How about responsiveness - are companies and corporations, on the one hand, and consumers, on the other hand, mutually responsive to what each other do? Or is there responsiveness only in one direction, or none at all? As discussed earlier, it looks like companies and corporations are responsive to what consumers do, because they risk their profit margin if they are not (they produce what they expect consumers to buy). But it doesn't look like this responsiveness is symmetrical. I won't try a precise numerical assessment here, but only comment that the purchases made by individual consumers will seldom if ever be central, and seldom if ever be planned in the relevant sense. They will, however, sometimes be proximal (either a trigger or a joint cause), usually not be reversible, and very often be repeated. So consumers are likely to get a high score when it comes to contribution.

The final element in Lepora \& Goodin's assessment of responsibility for complicity was shared purpose (ibid, pp. 107-109). The minimum requirement for complicity is that the agent knew or should have known about the contribution of their action to the relevant wrongdoing. But from that minimum there can be greater shared purpose, through to approval and fully sharing the wrongdoer's purpose. That is to say, having more of a pro-attitude to the principal's wrongdoing makes the complicity more responsible-although having a conattitude does not exonerate the complicity ('taking a negative attitude towards wrongdoing is the moral default', ibid, p. 109). The authors propose a 'more or 
less' ordering, depending on extent of overlap in purpose, strength of shared purpose, and action guidingness of shared purpose (ibid, p. 108). It is of course an empirical question whose answer will differ from consumer to consumer what consumers' attitudes are, but it seems not unreasonable to predict that most consumers' attitudes will range from the minimum through disapproval, and reluctance, to indifference (not usually getting to approval or fully shared purpose). Many are uncomfortable with the fact of global labour injustice. If that's right, then their complicity will be less responsible, even though not exonerated.

Admittedly, Lepora \& Goodin's framework is not particularly easy to apply. There are four 'conceptual cousins' and four ways of being a co-principal, in addition to the main way of being complicit simpliciter (and its sub-type). Even when we've managed to defend the application of one or more of these concepts to consumers taken individually, to establish moral responsibility for the relevant kind of complicity we have to look at four elements, one of which incorporates three further elements and another of which incorporates six further elements. Still, we're now in a position where we have consumer complicity in global labour injustice, and moral responsibility for that complicity. The problem that remains is that despite all the work they put into the conceptual distinctions, Lepora \& Goodin don't say anything about the content of the obligations that follow from morally responsible complicity. (From pp. 115 - 128 they apply the framework to cases, finding different characters to be complicit). What moral obligations does the complicit consumer have in light of her complicity? What are the legal sanctions appropriate to a complicit consumer? It's not easy to see how to fill this in on their account. But other accounts could be brought in to fill out the content at this point. Ole Koksvik \& Gerhard Øverland (ms.) propose that profit which depends on poverty should be redistributed among those on whose poverty it depends. As long as savings count as profit, and both those in exploited labour and those who would take their place count as in poverty, their account can give those complicit in labour injustice obligations to redistribute their profits. Avia Pasternak (2014) proposes that while an innocent beneficiary of injustice should disgorge the benefits, when a beneficiary is aware that she benefits, actively seeks out the benefit, desires the benefit, or does not avoid the benefit when she could do so at reasonable cost, her obligations may be to compensate the victims of 
injustice in excess of the extent to which she has benefits (ibid, pp. 387-388). Jeremy Dunham \& Holly Lawford-Smith have argued recently that innocent beneficiaries of structural injustice have obligations to offset their advantage, which they can do in a multitude of ways, and their list of suggestions could be appropriated here (although this would require thinking that the difference between duties based on innocently benefiting and duties based on complicity was a matter of degree rather than kind: that being complicit means you have to do more, rather than that you have to do different things) (Dunham \& Lawford-Smith 2017).

One worry about consumers being complicit in global labour injustice through their purchases and having obligations on that basis is that one might naturally expect their obligation to be to cease being complicit. After all, surely it's better not to be complicit in the first place, than to remain complicit and do various things to make up for it. Does this imply that ideally, consumers ought to be boycotting goods whose production histories involve injustice? ${ }^{10}$ Not necessarily. Given the lack of transparency in the supply chains of many products, and given the dearth (or entire absence) of alternative products that do not involve injustice, complete avoidance of complicity in global labour injustice may be impossible, or at the very least, overly demanding. In that case there would be no obligation not to be complicit; only obligations following from the (more or less unavoidable) fact of complicity. If that's right, then there's room to think more about what kinds of actions alleviate global labour injustice, and to look to these as the kinds of things that those complicit in global labour injustice ought to be doing.

\section{$\S$ VI. Conclusion}

I have argued that consumers are complicit in the global labour injustice primarily perpetrated by companies and corporations. They are defeasibly complicit in condoning the original injustice involved in the production of the goods they buy, defeasibly complicit in conniving in the past injustice involved in production and the future injustice created by demand. They are complicit simpliciter, in that their purchases come with an expectation of advancing the interests of companies

10 I'm grateful to an anonymous reviewer for pushing me on this point. 
and corporations in persisting with unjust and exploitative labour practices.

\section{References}

Dunham, Jeremy., \& Lawford-Smith, Holly. 'Offsetting Race Privilege', Journal of Ethics and Social Philosophy 11/2 (2017).

Kagan, Shelly. Do I Make a Difference? Philosophy and Public Affairs 39/2 (2011), 105-141.

Kelly, Annie. 'Bangladesh's garment workers face exploitation, but is it slavery?', The Guardian, 16th May 2013. Online at http://theguardian.com/global-development/povertymatters/2013/may/16/bangladesh-garment-workers-exploitation-slavery accessed 18th January 2017.

Koksvik, Ole. \& Øverland, Gerhard. 'Profiting From Poverty'. Manuscript as at April, 2016. Online at http://www.koksvik.net/files/koksvik_overland_illicit_profit_current.pdf accessed 7th February 2017.

Kutz, Christopher. Complicity (Cambridge: Cambridge University Press, 2007a).

Kutz, Christopher. 'Causeless Complicity', Criminal Law and Philosophy 1 (2007b), 289-305.

Lepora, Chiara. \& Goodin, Robert. Complicity and Compromise (Oxford: Oxford University Press, 2013).

Nefsky, Julia. 'Consequentialism and the Problem of Collective Harm: A Reply to Kagan', Philosophy and Public Affairs 39/4 (2012), pp. 364-395.

Pasternak, Avia. 'Voluntary Benefits from Wrongdoing', Journal of Applied Philosophy 31/4 (2014), pp. 377-391.

Riley, Charles. 'Bangladesh vows reform amid allegations of 'modern slavery', CNN Money, May 6th 2013. Online at http://money.cnn.com/2013/05/06/news/bangladesh-factory/index.html accessed 18th January 2017.

Shiffrin, Seana. 'Harm and Its Moral Significance', Legal Theory 18/3 (2012), pp. 357-398.

War on Want. 'Sweatshops in Bangladesh', 2017. Online at http://www.waronwant.org/sweatshops-bangladesh accessed 18th January 2017. 


\section{University Library}

\section{- M M N E R VA A gateway to Melbourne's research publications}

Minerva Access is the Institutional Repository of The University of Melbourne

Author/s:

Lawford-Smith, H

Title:

Does Purchasing Make Consumers Complicit in Global Labour Injustice?

Date:

2018-08-01

Citation:

Lawford-Smith, H. (2018). Does Purchasing Make Consumers Complicit in Global Labour Injustice?. RES PUBLICA-A JOURNAL OF MORAL LEGAL AND POLITICAL PHILOSOPHY, 24 (3), pp.319-338. https://doi.org/10.1007/s11158-017-9355-4.

Persistent Link:

http://hdl.handle.net/11343/283134 